\title{
Cost-effective risk-based inspection planning for offshore wind farms
}

\author{
A Koltsidopoulos Papatzimos, T Dawood and P R Thies
}

\begin{abstract}
Offshore wind farm assets require regular inspections. Studies and industry experience have highlighted the importance of selecting the appropriate inspection and maintenance (I\&M) plan, as it directly impacts the reliability of the components and the associated maintenance cost. If inspections are carried out too frequently, the associated risks will be low and reliability will be high, but the cost will also be high. On the contrary, if no or very few inspections are carried out, unexpected failures of the structures could occur. This paper presents a risk-based inspection (RBI) framework for offshore wind farms, building on existing knowledge from other industries including nuclear, oil \& gas, chemical and aerospace. This approach considers the probability, the consequences and the cost of the operational or maintenance activity via a criticality analysis that allows optimal selection and prioritisation of I\&M activities. A case study is presented where this framework is implemented on the transition pieces (TPS) of the wind turbines, by investigating information received from design, operation and inspection reports as well as monitoring equipment. Guidelines are also proposed on how to utilise novel monitoring and visual inspection techniques to further improve the implementation of RBI. The results of this paper suggest a less frequent I\&M strategy, which could reduce the associated TP inspection costs by up to

$£ 0.7$ million/MW installed and increase the safety of personnel. The study will be of interest to offshore wind farm developers, operators and maintenance providers, to better prioritise I\&M activities and increase the operating
\end{abstract} revenue of their assets.

\section{Introduction}

Monopile support structures represent $81 \%$ of the installed offshore wind turbine foundations in European waters ${ }^{[1]}$. A transition piece (TP) is needed in order to connect the wind turbine tower with the monopile. A typical offshore wind turbine monopile foundation and its TP are shown in Figure $1^{[2]}$. Regular internal and external inspections of the TP are required in order to avoid any failures on the grouted connections between the TP and the monopile (see Figure 1). A failure of the grouted connection resulted in the TP starting to slip down the monopile at the Robin Rigg offshore wind farm in $2010^{[3]}$, due to an oversight in the DNV standards ${ }^{[4]}$. The standards were then revised, suggesting additional support arrangement to existing structures and a new small cone angle in the grouted connection ${ }^{[5]}$. Typically, grouted connections can be monitored via structural health monitoring (SHM) systems and in-situ inspection of the grout thickness. Other failure mechanisms include internal corrosion issues as well as external corrosion, aggravated by biofouling. The challenging accessibility of both internal and external locations requires a specific and targeted inspection intervention. A common approach is to perform annual inspections on either all or a sample of the wind turbine TPs. This usually includes all of the internal and external access equipment, along with any mechanical, welded and electrical connections. However, this is a time-consuming and costly process, taking into account that most of the inspected structural components have an expected lifetime that exceeds the 20 -year designed lifetime of the wind $\mathrm{farm}^{[6]}$. At the same time, several of these inspections have the opportunity to be combined with other planned operations, to share resources and reduce costs.

Consequently, the concepts of reliability-centred maintenance $(\mathrm{RCM})$, risk-based inspection (RBI) and risk-based maintenance (RBM) have been developed and successfully implemented in several industries, including aerospace ${ }^{[7]}$, chemical ${ }^{[8]}$, oil \& gas ${ }^{[9]}$ and nuclear ${ }^{[10]}$. Frameworks and studies have been computationally applied in the offshore wind industry ${ }^{[11]}$, but the offshore wind farm operators are still sceptical in the implementation of such a framework, mainly due to the lack of field data. The main difference between RCM and RBI/RBM lies in the level of analysis undertaken to define maintenance and inspection intervals. Where cost-risk optimisation is incorporated to help tailor maintenance regimes, it is considered an RBI technique ${ }^{[12]}$. Both methods show an attempt to utilise the existing knowledge of the asset in order to perform future maintenance actions effectively and to reduce the associated overall costs. As operational cost reduction is a critical aspect for future offshore wind farm projects, this study investigates RBI techniques.

The definition of risk depends on the context in which it is applied. A recent review article has identified and grouped the different definitions of risk concepts into the following ${ }^{[13]}$ : expected consequences; probability and scenarios/consequences/ severity of consequences; event or consequence; consequences/ damage/severity of these and uncertainty; and the effect of

\section{Submitted 12.09.17 / Accepted 07.12.17}

Alexios Koltsidopoulos Papatzimos* and Tariq Dawood are with EDF Energy R\&D UK Centre, 81-85 Station Road, London CRO 2AJ, UK.

Alexios Koltsidopoulos Papatzimos is also with the Industrial Doctorate Centre for Offshore Renewable Energy (IDCORE), University of Edinburgh, Edinburgh EH8 8FF, UK.

Philipp R Thies is with the University of Exeter, Penryn Campus, Penryn, Cornwall TR10 9FE, UK.

*Corresponding author. Email: a.koltsidopoulos-papatzimos@ed.ac.uk 


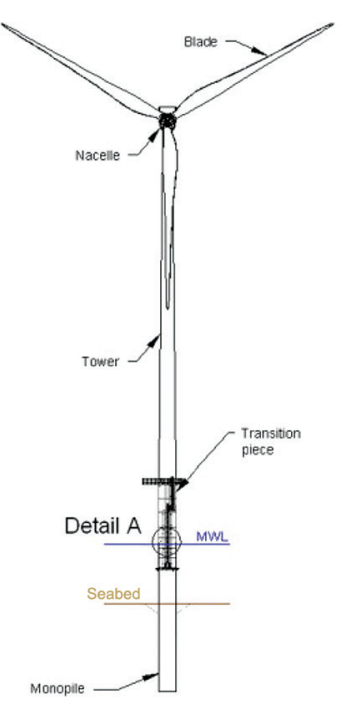

General arrangement

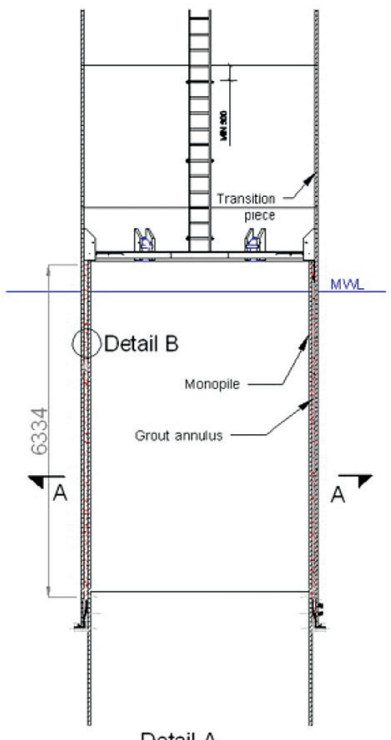

Detail A

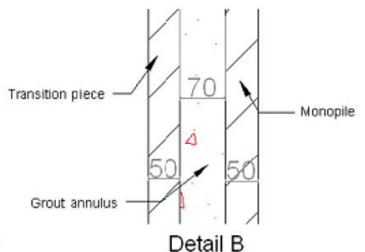

Detail B

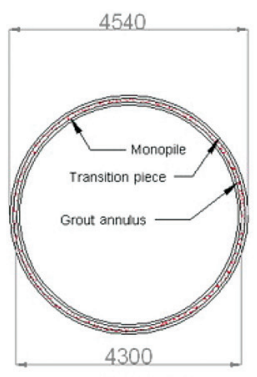

Elevation A-A
Figure 1.Typical offshore wind monopile foundation with the TP on the left and the grouted connection on the right ${ }^{[2]}$ uncertainty on objectives. ISO standards have defined risk as a measure of the likelihood of failure and its potential impact ${ }^{[14]}$. This could refer to the system as a whole or to its individual components, as well as to people, the environment and economic losses $^{[15]}$. It is usually assessed by a risk matrix that includes the likelihood ( $y$-axis) and consequences ( $x$-axis) of failure. Several authors have challenged the effectiveness of a risk matrix and its outputs ${ }^{[16,17]}$. As an effect, recent improvements to the above definition have also added an uncertainty interval to the equation ${ }^{[18]}$. Regardless of the various weaknesses of this method, it is still considered a robust, pragmatic method that is applied by several industries today.

Despite the evident cost reduction opportunities of risk-based operations ${ }^{[19]}$ and the successful implementation in other industries, research and implementation in the offshore wind field is limited. This risk-based inspection and maintenance (I\&M) operations, by applying the proposed framework to operational datasets.

A generic RBI framework developed for offshore wind farm applications is introduced, building on existing approaches in other industry sectors. This framework is applied and further refined by incorporating monitoring and inspection data from the 62.1 MW Teesside offshore wind farm. The study yields different cost scenarios and discusses the potential for tangible cost reductions and future applications of the framework.

\section{Methodology}

This section proposes an RBI framework that is later tested for TP inspections. It has been created based on common approaches paper aims to emphasise the benefits of in other industries ${ }^{[7,8,9,10]}$. An applied RBI technique is proposed that comprises four main stages, as shown in Figure 2, which create a loop in order to improve future I\&M in more detail in the following subsections.

\subsection{Initial decision and evaluation}

The initial decision and evaluation stage includes the sample size, the location of the turbines and the identification of the components that need to be inspected. It is common practice to select an inspection sample. This is usually a large number during the first inspections and can be reduced later on, as this is a dynamic decision process that needs to be reevaluated at every inspection interval. Once the turbine sample and location have been defined, a risk matrix can be created for all of the inspected components. A typical risk matrix used is shown in Table 1 . The numbers on the matrix are solely for reference purposes, which are used later on in the model. This is an initial screening step to eliminate those components that will not need to be inspected. The information can be generated by considering previous inspection reports and understanding the potential failures and their impact. This process significantly reduces the amount of time needed for the RBI, as fewer components will be considered. planning. The individual phases are described

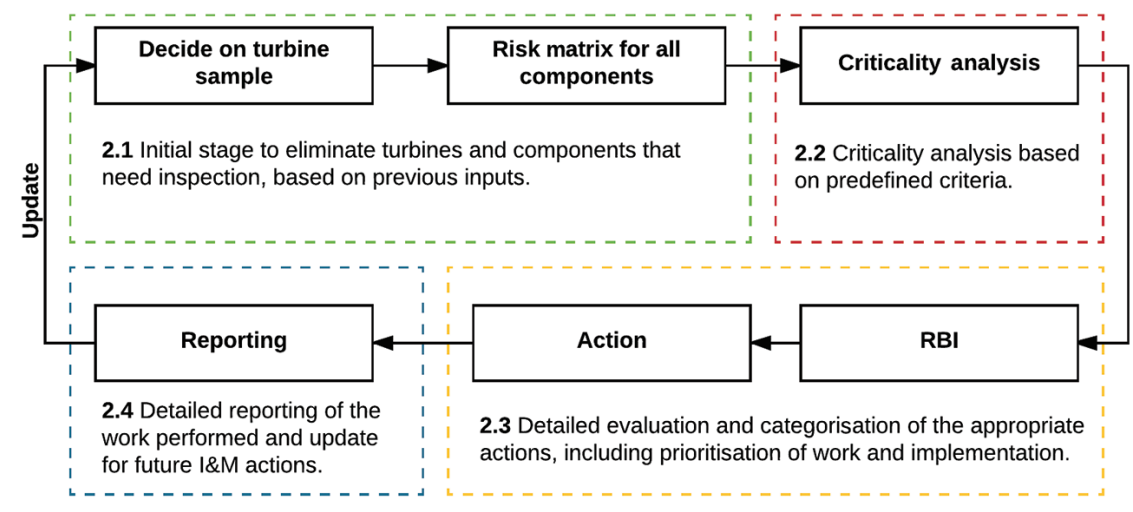

Figure 2. High-level overview of the RBI framework

Table 1. Risk matrix

\begin{tabular}{|c|c|c|c|c|c|c|}
\multicolumn{2}{c|}{} & \multicolumn{5}{c|}{ Impact } \\
\cline { 3 - 8 } \multicolumn{2}{c|}{} & Very low & Low & Medium & High & Very high \\
\hline \multirow{5}{*}{ Probability } & Very high & 8 & 11 & 19 & 21 & 25 \\
\cline { 2 - 8 } & High & 7 & 10 & 14 & 20 & 24 \\
\cline { 2 - 8 } & Medium & 3 & 9 & 13 & 17 & 23 \\
\cline { 2 - 8 } & Low & 2 & 5 & 12 & 16 & 22 \\
\cline { 2 - 8 } & Very low & 1 & 4 & 6 & 15 & 18 \\
\hline
\end{tabular}

\subsection{Criticality analysis (CA)}

Once the initial screening stage is complete, a criticality analysis (CA) is performed on the remaining components, as developed and shown in Figure 3. 


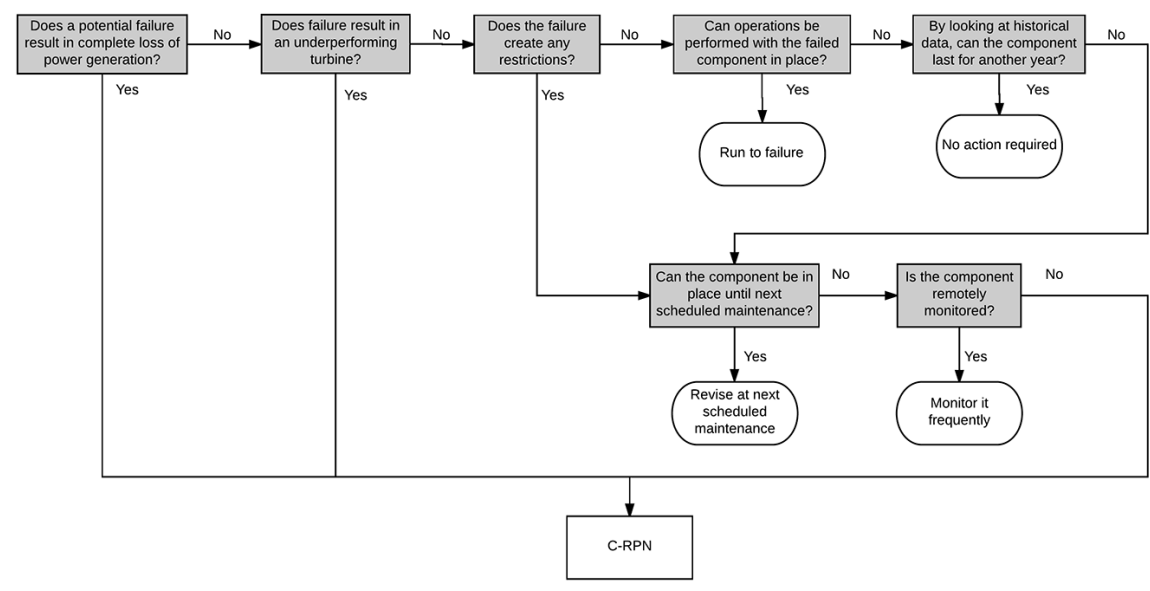

Figure 3. Criticality analysis steps

The cost-risk priority number (C-RPN) is calculated by taking into consideration the difference of the failure $\operatorname{cost}\left(C_{D}\right)$, the severity of effect $(S)$ or the severity of restriction $(R)$ that the failure could create, the occurrence probability $(O)$ and the detection method $(D)$, as shown in Equations (1) and (2):

$$
\begin{aligned}
& \mathrm{C}-\mathrm{RPN}=C_{D} * S * O * D . \\
& \mathrm{C}-\mathrm{RPN}=C_{D} * R * O * D .
\end{aligned}
$$

where $S, O, D$ and $R$ are integers in the range 1-10, given by definitions in Table 2. Depending on the consequences of the severity in terms of production effects or restriction issues, the $S / R$ values can be decided. In most of the cases it is clear whether the severity affects the operations or the power production of the wind farm, but if there is a case where both are affected it is suggested that the highest C-RPN number be taken into consideration.
$C_{D}$ (Equation (3)) is the difference between the total loss without corrective action $\left(C_{a}\right)$ and the total expected loss after corrective action $\left(C_{n}\right)$. If the value is negative, the implementation of the maintenance action should be reconsidered by initially checking if there are any restrictions or safety issues that might be caused if the issue is not fixed:

$$
C_{D}=C_{a}-C_{n}
$$

Guidance on how to define the different $S, R, O$ and $D$ values is given in Table 2. The initial thresholds have been specified in ${ }^{[20]}$. The risk priority number (RPN) criteria have been further refined in order to reflect the offshore wind turbine operations, including remote monitoring systems (RMSs), non-destructive testing (NDT) inspections and potential restrictions. RMSs include any type of supervisory control and data acquisition (SCADA), condition monitoring (CM) and SHM systems.

\subsection{RBI implementation}

Once a CA has been performed and the high RPN operations have been defined, RBI can be applied (Figure 4). The framework evaluates the severity and importance of the operation. Low importance is an occasion that can be fixed easily with basic tooling and, as a result, the action can be immediately planned. In the cases of medium and high importance, further processes are followed in order to identify the root cause of the problem via failure mode, effects and criticality analysis (FMECA). This will ensure that the causes are well understood and that preventative measures are implemented in order to avoid any similar future failures. Finally,

\begin{tabular}{|c|c|c|c|c|c|}
\hline$\#$ & Severity of effect $(S)$ & $\begin{array}{c}\text { Occurrence } \\
\text { probability }(O)\end{array}$ & Likelihood of RMS detection $(D)$ & $\begin{array}{l}\text { Likelihood of NDT } \\
\text { detection }(D)\end{array}$ & $\begin{array}{l}\text { Severity of } \\
\text { restrictions }(R)\end{array}$ \\
\hline 1 & No effect & $\begin{array}{c}<1 \text { in } \\
1,500,000\end{array}$ & $\begin{array}{l}\text { RMS will certainly detect a failure } \\
\text { cause/failure mode }\end{array}$ & \multirow{3}{*}{$\begin{array}{l}\text { The failure can also be } \\
\text { identified by inspection } \\
\text { during operations }\end{array}$} & No restrictions \\
\hline 2 & $\begin{array}{l}\text { Very minor effect on power } \\
\text { production }\end{array}$ & 1 in 150,000 & $\begin{array}{l}\text { Very high chance the RMS will detect } \\
\text { a failure cause/failure mode }\end{array}$ & & $\begin{array}{l}\text { Very minor } \\
\text { restrictions }\end{array}$ \\
\hline 3 & $\begin{array}{l}\text { Minor effect on power } \\
\text { production }\end{array}$ & 1 in 15,000 & $\begin{array}{l}\text { High chance the RMS will detect a } \\
\text { failure cause/failure mode }\end{array}$ & & Minor restrictions \\
\hline 4 & $\begin{array}{c}\text { Small effect on power } \\
\text { production, repair not required }\end{array}$ & 1 in 2,000 & $\begin{array}{l}\text { Moderately high chance the RMS will } \\
\text { detect a failure cause/failure mode }\end{array}$ & \multirow{2}{*}{$\begin{array}{l}\text { The failure might also be } \\
\text { identified by inspection } \\
\text { during operations }\end{array}$} & $\begin{array}{l}\text { Few restrictions, } \\
\text { repair not required }\end{array}$ \\
\hline 5 & $\begin{array}{l}\text { Moderate effect on power } \\
\text { production, repair required }\end{array}$ & 1 in 400 & $\begin{array}{l}\text { Moderate chance the RMS will detect } \\
\text { a failure cause/failure mode }\end{array}$ & & $\begin{array}{l}\text { Moderate restrictions, } \\
\text { repair required }\end{array}$ \\
\hline 6 & $\begin{array}{c}\text { Component performance is } \\
\text { degraded }\end{array}$ & 1 in 80 & $\begin{array}{l}\text { Low chance the RMS will detect a } \\
\text { failure cause/failure mode }\end{array}$ & \multirow{2}{*}{$\begin{array}{l}\text { Visual inspection is } \\
\text { needed to detect the } \\
\text { failure }\end{array}$} & \multirow{2}{*}{$\begin{array}{l}\text { Severe restrictions, } \\
\text { repair required to } \\
\text { continue operations }\end{array}$} \\
\hline 7 & $\begin{array}{l}\text { Component is severely affected, } \\
\text { turbine may not operate }\end{array}$ & 1 in 20 & $\begin{array}{l}\text { Very low chance the RMS will detect } \\
\text { a failure cause/failure mode }\end{array}$ & & \\
\hline 8 & $\begin{array}{l}\text { Component is inoperable with } \\
\text { loss of primary function }\end{array}$ & 1 in 8 & $\begin{array}{l}\text { Remote chance the RMS will detect a } \\
\text { failure cause/failure mode }\end{array}$ & \multirow{3}{*}{$\begin{array}{l}\text { Need NDT monitoring } \\
\text { equipment to detect the } \\
\text { failure }\end{array}$} & \multirow{3}{*}{$\begin{array}{l}\text { Restrictions do not } \\
\text { allow safe access to } \\
\text { the turbine }\end{array}$} \\
\hline 9 & $\begin{array}{l}\text { Failure involves hazardous } \\
\text { outcomes }\end{array}$ & 1 in 3 & $\begin{array}{l}\text { Very remote chance the RMS will } \\
\text { detect a failure cause/failure mode }\end{array}$ & & \\
\hline 10 & $\begin{array}{c}\text { Failure is hazardous and occurs } \\
\text { without warning, turbine } \\
\text { operation is suspended }\end{array}$ & $>1$ in 2 & $\begin{array}{l}\text { RMS will not detect a failure cause/ } \\
\text { subsequent failure mode }\end{array}$ & & \\
\hline
\end{tabular}
the maintenance actions can be planned.

Table 2. RPN detailed criteria ranking 


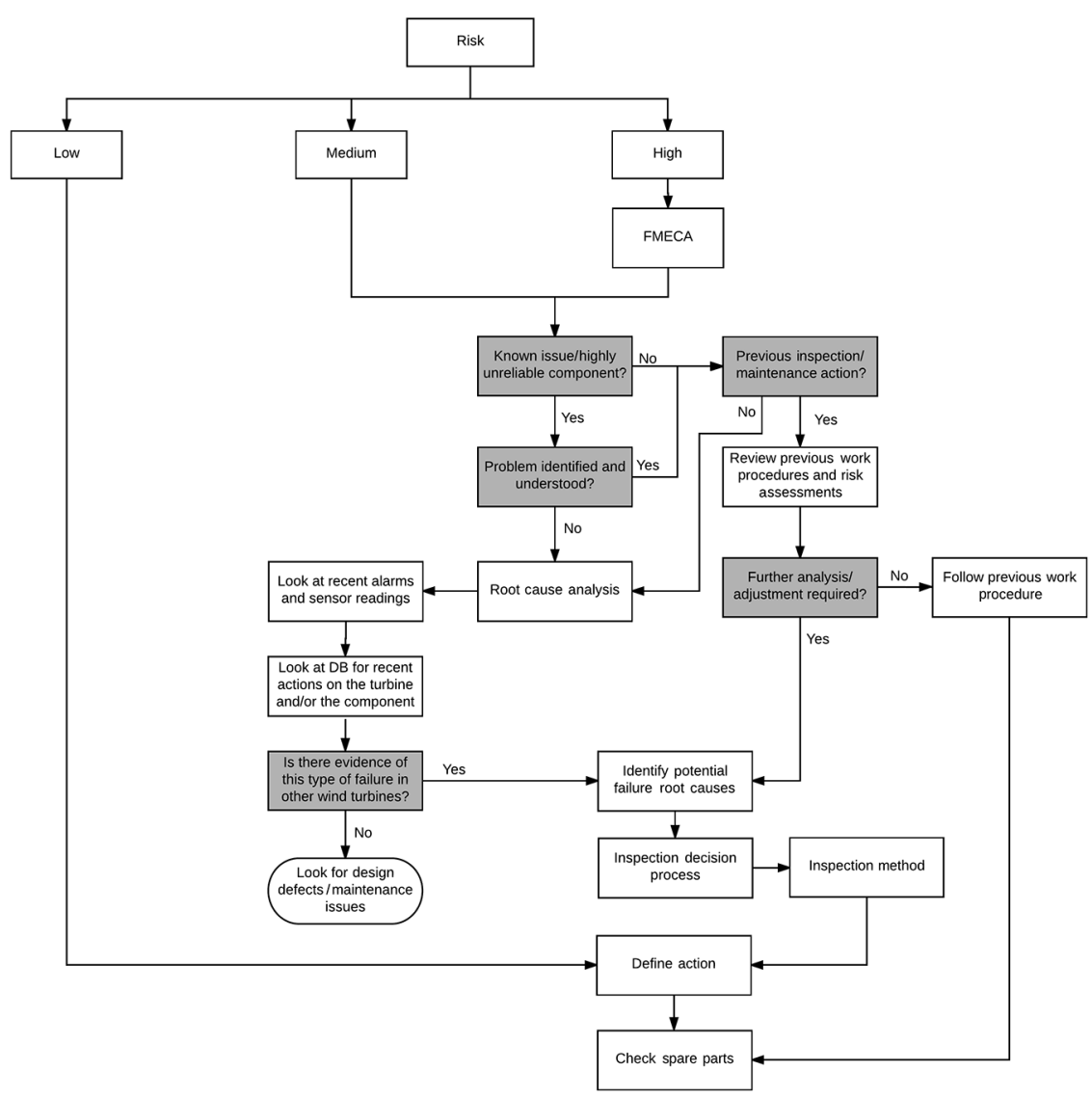

Figure 4. RBI plan detailed breakdown

\subsection{Reporting}

The final step is the reporting of the executed I\&M information. This is a very important step and the information has to be recorded in such a way so that it can be easily retrieved and related to other sources. At the same time, the information needs to feed forward to update the current status of the assets and be able to advise future I\&M decisions.

\section{Case study}

Based on the approach presented, a case study for RBI of offshore wind TPs is presented here. The site considered for this study is the 62.1 MW Teesside offshore wind farm, comprising 27 Siemens 2.3 MW turbines. A bespoke model is initially built and eight different inspection strategies are considered.

\subsection{Model}

The proposed model is presented in Figure 5 and includes inputs from different sources, which are presented in the following subsections. Inputs include estimated costs, comments from operations and inspection reports and data from the SHM systems and any corrosion measurements. Inputs are not weighted, but they can be prioritised via the criticality analysis or the triggering of immediate actions. These are combined in the model where a sequential Monte Carlo simulation (MCS) is used to generate inspection scenarios that would be required through the lifetime of the structure. The model runs a two-state Markov chain from the generated inputs by considering the mean time for a required inspection and its mean duration time, as defined by the input findings. The time for a required inspection is defined by the occurrence probability. Similar Markov chain models have been used in the literature in order to estimate the reliability and availability of engineering systems $^{[21,22]}$.

\subsubsection{Cost data}

Some basic estimated cost data have been assumed for onshore (including planning and report writing) and offshore (including vessel hire, transport and personnel cost) operations. An overview of some of the assumptions used to model the costs can be found in Table 3 . The method used for collecting some of this information is presented in ${ }^{[23]}$.

\subsubsection{Comments from operations}

Another input is the assumption that certain inspections can be performed and logged by maintenance personnel during scheduled operations. These are the ones identified in Table 2 with $D<5$, such as signs of external biofouling, paintwork or internal lighting. They can then be used alongside the inspection reports, either to update the information received from them or to report new issues.

Table 3. Overview of assumptions for baseline cases used to model the costs

\begin{tabular}{|c|c|}
\hline Number of days & 3 \\
\hline Number of turbines inspected & 6 \\
\hline Number of technicians & 4 \\
\hline Average inspection time per turbine $(\mathrm{h})$ & 3 \\
\hline Distance from port $(\mathrm{km})$ & 7 \\
\hline Distance between turbines $(\mathrm{km})$ & 0.5 \\
\hline Transfer time per turbine $(\mathrm{min})$ & 10 \\
\hline Vessel mob/demob time $(\mathrm{min})$ & 30 \\
\hline
\end{tabular}

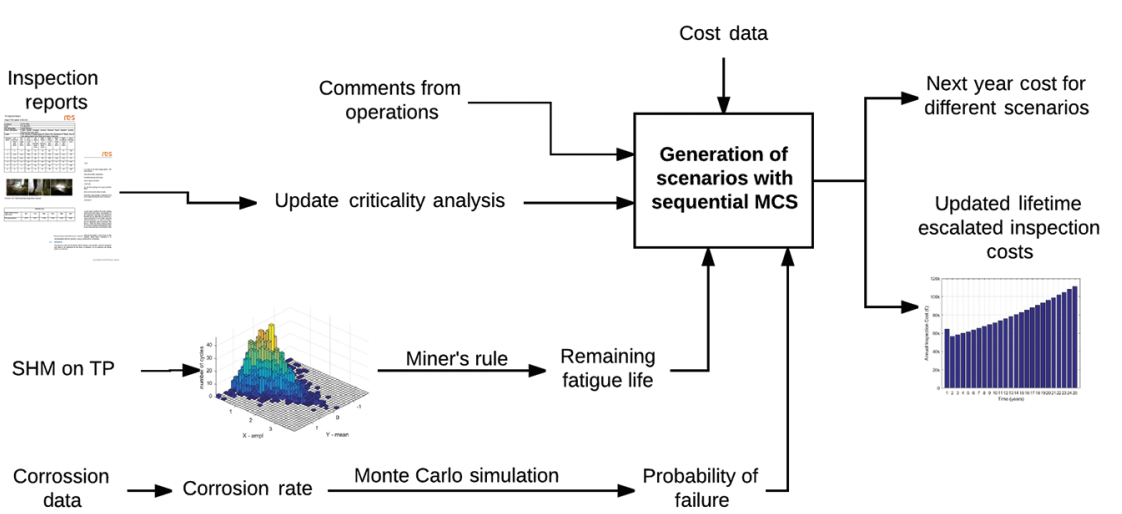

Figure 5. Overview of the proposed model for TP RBI planning 


\subsubsection{Inspection report information}

With the current knowledge from the latest TP inspection activities, the different components inspected have been positioned on the risk matrix (Table 1). This is a first quick check to assess the severity of the different component inspections, without moving to their C-RPN number. Table 2 defines the $S / R, O$ and $D$ values for the different components. The final values, used in Equations (1) and (2) to prioritise the inspection activities in the model, are shown in Tables 4 and 5. Time has also been assigned to each of the tasks, which allows the model to run more accurate inspection time estimates when some of the tasks are not performed.

\subsubsection{Structural health monitoring (SHM)}

The SHM system in place can flag any immediate actions needed on the structure and can also allow for making predictions of the fatigue lifetime of the different components inspected. Usually, a representative sample of turbines are fitted with SHM systems where the harshest environmental conditions are expected. This study uses existing SHM systems and performs an analysis of the strain gauge information received. A state-of-the-art review of damage detection methods has been completed in ${ }^{[24]}$. SHM systems can operate in parallel with the scheduled I\&M operations for contingency and in order to be able to identify any unexpected failure modes. This could trigger either an immediate inspection or allow for prioritisation of the inspection activities in the coming inspection interval.

The relevant strain gauge sensors are monitored on the TP. The data collected were converted into stresses and a rainflow diagram was constructed in order to be able to calculate the number of cycles, as indicated in ${ }^{[25]}$. Finally, by using the Miner's damage hypothesis ${ }^{[26]}$, the total damage of the structure was calculated, as shown in Equation (4):

$$
\sum_{i=1}^{k} \frac{n_{i}}{N_{i}}=C
$$

where $n_{i}$ is the number of cycles accumulated at stress $\sigma_{i}$ and $C$ is the accumulated damage, where 1 indicates failure. The expected lifetime of the component inspected was then calculated by dividing the time interval used by the accumulated damage.

\subsubsection{Corrosion data}

The corrosion data were used in order to determine the probability of failure (POF) of the structure due to corrosion. An approach introduced in $^{[27]}$ was followed. The remaining life (RL) of the structure was initially calculated using Equation (5) ${ }^{[28]}$ :

$$
R L=\frac{t_{\text {actual }}-t_{\text {required }}}{C R}
$$

where $t_{\text {actual }}$ is the current thickness of the structure, $t_{\text {required }}$ is the minimum allowable thickness defined by the design reports and CR is the corrosion rate of the structure. $t_{\text {actual }}$ can be calculated at any given year, $y$, using Equation (6), where $t_{0}$ is the original designed thickness:

$$
t_{\text {actual }}=t_{0}-C R * y
$$

From the design reports ${ }^{[29]}, t_{\text {actual }}=4200 \mathrm{~mm}$ and a corrosion allowance of $7.5 \mathrm{~mm}$ was used. An indicated $\mathrm{CR}=0.3 \mathrm{~mm} /$ year was considered in the standards ${ }^{[30]}$. These data are recommended to be updated by experimental or field studies and observations. In this study, a more conservative $\mathrm{CR}=0.4 \mathrm{~mm} /$ year was considered in order to reduce any associated risks. CR and $t$ are presumed to have normal distributions, assuming a uniform corrosion ${ }^{[31]}$ with standard deviations of 0.1 and 1 , respectively. The POF can finally be calculated by using an MCS to define the values of Equation 5, when the criterion shown in Equation 7 is met. A graphical representation of the results is shown in Figure 6:

$$
\mathrm{POF}=P(R L \leq 0)
$$

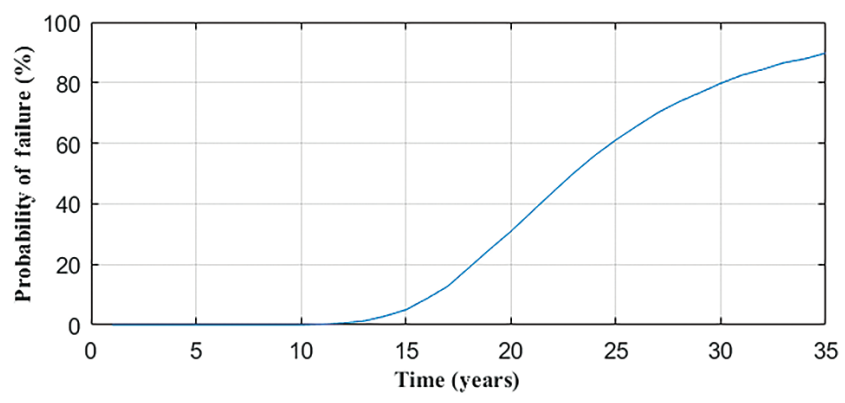

Figure 6. Estimated annual probability of failure of the TP

\subsection{Scenarios}

Eight different test cases have been considered. Baselines 1 (B1) and 2 (B2) represent the typical inspection plans that wind farm

Table 4. RM and $S / R, O$ and $D$ ranking for internal TP inspections

\begin{tabular}{|c|c|c|c|c|c|c|c|c|c|c|c|c|c|c|}
\hline & $\begin{array}{c}\text { Access } \\
\text { ladders }\end{array}$ & Lighting & Ventilation & $\begin{array}{c}\text { Lighting } \\
\text { protection }\end{array}$ & $\begin{array}{c}\text { Fall } \\
\text { arrest }\end{array}$ & Flooring & Hatches & $\begin{array}{c}\text { Airtight } \\
\text { platform }\end{array}$ & $\begin{array}{c}\text { Airtight } \\
\text { hatch }\end{array}$ & $\begin{array}{c}\text { Cable } \\
\text { hang-off }\end{array}$ & $\begin{array}{c}\text { Belzona } \\
\text { coating }\end{array}$ & $\begin{array}{c}\text { Flange } \\
\text { welds }\end{array}$ \\
$\begin{array}{c}\text { Grout } \\
\text { thickness }\end{array}$ \\
\hline RM & 16 & 20 & 16 & 16 & 16 & 23 & 16 & 16 & 16 & 16 & 20 & 11 & 11 \\
\hline$S / R$ & 8 & 8 & 8 & 10 & 7 & 5 & 7 & 6 & 6 & 6 & 8 & 4 & 4 \\
\hline$O$ & 1 & 1 & 3 & 1 & 1 & 1 & 1 & 1 & 1 & 1 & 1 & 1 & 1 \\
\hline$D$ & 5 & 3 & 6 & 8 & 6 & 5 & 8 & 2 & 5 & 3 & 3 & 8 & 9 \\
\hline
\end{tabular}

Table 5. RM and $S / R, O$ and $D$ ranking for external TP inspections

\begin{tabular}{|c|c|c|c|c|c|c|c|c|c|c|c|c|}
\hline & $\begin{array}{c}\text { Turbine ID } \\
\text { sign }\end{array}$ & $\begin{array}{c}\text { Marine } \\
\text { growth }\end{array}$ & $\begin{array}{c}\text { Paint } \\
\text { work }\end{array}$ & $\begin{array}{c}\text { Access } \\
\text { ladder }\end{array}$ & $\begin{array}{c}\text { Access } \\
\text { gates }\end{array}$ & $\begin{array}{c}\text { Structure } \\
\text { bolts }\end{array}$ & $\begin{array}{c}\text { Safety } \\
\text { signage }\end{array}$ & Platform & Cabling & $\begin{array}{c}\text { Navigation } \\
\text { aids }\end{array}$ & Life buoy \\
\hline RM & 1 & 20 & 13 & 15 & 6 & 6 & 4 & 4 & 15 & 15 & 15 \\
\hline$S / R$ & 1 & 7 & 5 & 2 & 5 & 6 & 4 & 5 & 8 & 8 & 8 \\
\hline$O$ & 1 & 8 & 7 & 1 & 1 & 1 & 1 & 1 & 1 & 2 & 1 \\
\hline$D$ & 1 & 1 & 3 & 2 & 2 & 8 & 3 & 2 & 8 & 8 & 1 \\
\hline
\end{tabular}


operators are following. B1 considers the inspection of a sample of 6 out of the 27 turbines, throughout the lifetime of the wind farm, where the same TP components are inspected annually. B2 assumes that the inspection operations are performed in combination with other maintenance activities, so in this case the transport costs are shared between the two. In reality, the actual estimated costs would be somewhere in the middle, as it is not always possible to plan both I\&M operations at the same time. Both B1 and B2 represent very lowrisk inspection strategies, since all of the components are thoroughly inspected every year. These two cases are visualised in Figure 7, where the escalated annual costs at a rate of $3 \%$ are shown. At year 1, a oneoff tooling and equipment cost is assumed for all of the cases.

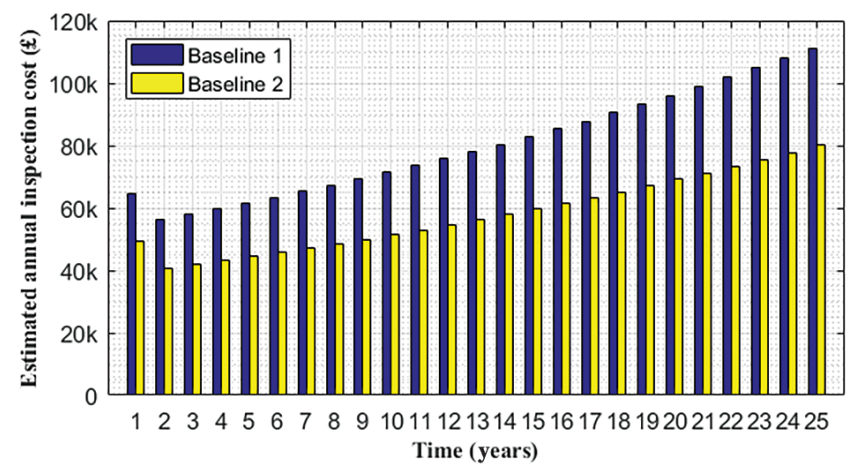

Figure 7. Annual escalated costs for B1 and B2 inspection plans

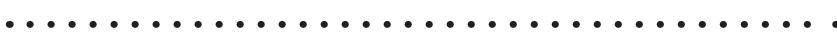

Below is a brief description of the assumptions considered in the different scenarios (S):

1. Full internal inspections are performed and high RPN of failure of external inspections for the first years, until POF of the structure exceeds 1\% (Section 3.1.5).

2. Full internal inspections are performed, whereas external ones are completed during regular operations (Section 3.1.2 and Section 3.1.5).

3. Similar to S2, with reduced internal inspections, assuming there is an SHM system in place on two representative turbines (Section 3.1.4).

4. Same as $\mathrm{S} 3$ but with biannual inspections.

5. Same as $\mathrm{S} 4$ but with a reduced turbine sample of 3 .

6. Same as $S 4$ but with an increased turbine sample of 9 .

The estimated lifetime costs for the different scenarios can be found in Table 6, along with the qualitative risk levels for years 1-12 and $13-25$ when POF of the structure $>1 \%$.

Table 6. Estimated lifetime costs for the different test cases escalated for 25 years, along with the associated inspection risk levels

\begin{tabular}{|c|c|c|c|c|c|c|c|c|c|}
\hline & B1 & B2 & S1 & S2 & S3 & S4 & S5 & S6 \\
\hline \multicolumn{2}{|c|}{ Cost ( $£$ million) } & 2.005 & 1.447 & 1.411 & 1.040 & 0.839 & 0.438 & 0.434 & 0.442 \\
\hline \multirow{2}{*}{$\begin{array}{l}\text { Risk } \\
\text { level }\end{array}$} & $\begin{array}{l}\text { Years } \\
1-12\end{array}$ & $\begin{array}{l}\text { Very } \\
\text { low }\end{array}$ & $\begin{array}{l}\text { Very } \\
\text { low }\end{array}$ & Low & Low & Low & Medium & High & Medium \\
\hline & $\begin{array}{c}\text { Years } \\
13-25\end{array}$ & $\begin{array}{l}\text { Very } \\
\text { low }\end{array}$ & $\begin{array}{l}\text { Very } \\
\text { low }\end{array}$ & $\begin{array}{l}\text { Very } \\
\text { low }\end{array}$ & $\begin{array}{l}\text { Very } \\
\text { low }\end{array}$ & $\begin{array}{l}\text { Very } \\
\text { low }\end{array}$ & Low & Medium & Low \\
\hline
\end{tabular}

Finally, another output of the model is a cost estimate for the different test cases considered in the following years. Since the model is designed to be updated on an annual basis, there is no need to show a longer period of cost estimates as these values would alter depending on the inputs and will not be representative.

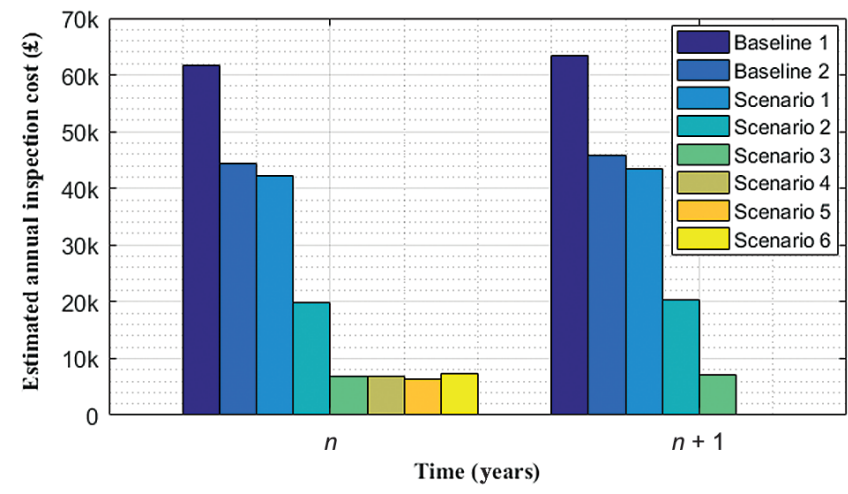

Figure 8. Example cost output for years $n$ and $n+1$

An example for years $n$ and $n+1$ is shown in Figure 8. S4, S5 and S6 are biannual and thus not shown at year $n+1$.

\section{Discussion and conclusions}

This paper has provided a pragmatic and practical framework to implement RBI for offshore wind farms. A unique model is presented to perform risk-based TP inspections by incorporating different operational data. Different scenarios are tested to understand the influence of various operational parameters to the overall TP inspection costs. At the same time, a trade-off is presented between lower costs and higher risk that should be investigated when selecting an inspection strategy. From Table 6, it is evident that:

- B1 and B2 are the highest cost and lowest risk cases.

- $\mathrm{S} 5$ is the lowest cost and highest risk case.

- S3 is the most balanced case, offering a reduced cost and low or very low risk. This is achieved with the introduction of SHM systems.

Moreover, the next year cost estimates shown in Figure 8 can provide a better understanding of the short-term cost benefits for the different scenarios. It can also allow the end-user to implement different scenarios at each inspection interval, by evaluating the costs and associated risks.

These test cases are just an example and have been created in order to highlight the importance of utilising operational data for upcoming inspections. It is evident from the results of the case studies that there are significant cost reduction opportunities when following risk-based operations. Furthermore, by introducing the restriction metric $(R)$ in the C-RPN equation, safety becomes a priority when maintenance actions are ranked.

In the case of Teesside offshore wind farm, it was shown that:

- Encouraging reporting of failed components during regular maintenance operations can reduce inspection costs by up to $26 \%$, just by minimising work duplication, while maintaining low risk levels, as comparison of S1 and S2 costs indicates.

- Introduction of SHM can decrease inspection costs by up to $19 \%$, as shown in S3.

- Reducing or increasing the turbine sample size during inspection, from 6 to 3 or 9, does not have a significant effect on cost, as shown in S4, S5 and S6, respectively. 
Limitations of this study could include the early stages of the offshore wind industry, which would result in unexpected failure mechanisms and lower estimated costs for the lifetime of the asset. To tackle this issue, frequent monitoring and analysis of the SHM systems is suggested. Moreover, this study does not provide a detailed analysis of all of the potential failure mechanisms and assumes the use of a commercial SHM system. The potential cost and level of detailed analysis that can be invested in such systems is up to the user and there is always a cost-benefit analysis that needs to be considered. As an effect, only the benefits in daily observations and measurements (O\&M) are presented, as this paper makes the case for a holistic approach when it comes to I\&M decision making.

Further findings of this paper show that it is important to implement the RBI framework throughout the lifetime of the project to gain the relevant knowledge from an early stage and increase the confidence in the inputs. At the same time, it is vital to update the model at least once a year, allowing for a better understanding of the future actions required.

Future work will focus on incorporating more field data and testing the model, as well as developing it further to include more inspection equipment. Additional work could include sensitivity analysis of the inputs of the models, which could indicate the importance of different factors in relation to the estimated inspection costs, such as that performed in ${ }^{[32]}$. Finally, the RBI framework will be modified to perform risk-based maintenance actions.

\section{Acknowledgements}

This research was funded by the Energy Technology Institute and the RCUK Energy Programme (Grant number: EP/J500847/1) and EDF Energy. The authors would like to thank EDF Energy Renewables for providing access to the required data.

\section{References}

1. W B Intelligence, 'The European offshore wind industry - Key trends and statistics 2016', Wind Europe, Brussels, Belgium, 2016.

2. P Dallyn, A El-Hamalawi, A Palmeri and R Knight, 'Experimental testing of grouted connections for offshore substructures: a critical review', Structures, Vol 3, pp 90-108, 2015.

3. J Quilter, 'Wind energy owners combine to investigate offshore foundation fault', Windpower Monthly, 9 April 2010. Available at: http://www.windpowermonthly.com/article/995751/windenergy-owners-combine-investigate-offshore-foundation-fault (Accessed: 13 July 2017).

4. T Price, 'Grouting still a major issue for offshore wind', Renewable energy magazine, 4 January 2012. Available at: https://www.renewableenergymagazine.com/wind/groutingstill-a-major-issue-for-offshore (Accessed: 13 November 2017).

5. DNV, 'DNV-OS-J101 - Design of offshore wind turbine structures', 2010.

6. DNV-GL, 'DNVGL-ST-0262 - Lifetime extension of wind turbines', 2016.

7. NASA, 'Reliability-centred maintenance guide', National Aeronautics and Space Administration, 2008.

8. D Richards, 'Risk-based maintenance', ABB Industries, 2002.

9. DNV, 'Recommended proactive DNV-RP-G101 - risk-based inspection of offshore topsides static mechanical equipment', 2010.

10. W A Soares, V D Vasconcelos and E G Rabello, 'Risk-based inspection in the context of nuclear power plants', Proceedings of the International Nuclear Atlantic Conference - INAC, São
Paolo, Brazil, 4-9 October 2015.

11. J D Sørensen, 'Framework for risk-based planning of operation and maintenance for offshore wind turbines', Wind Energy, Vol 12, No 5, pp 493-506, 2009.

12. Balfour Beatty Rail Technologies, 'Review of asset management best practice, Crown, 2012.

13. T Aven, 'The risk concept - historical and recent development trends', Reliability Engineering and System Safety, Vol 99, pp 33-44, 2012.

14. ISO/FDIS 31000:2009, 'Risk Management - Principles and Guidelines', 2009.

15. F P Lees, Loss Prevention in the Process Industries, ButterworthHeinemann, 1996.

16. L A Cox, 'What's wrong with risk matrices?', Risk Analysis, Vol 28, No 2, pp 497-512, 2008.

17. P Thomas, R B Bratvold and J E Bickel, 'The risk of using risk matrices', SPE Economics \& Management, Vol 6, No 2, pp 56-66, 2014.

18. T Aven, 'Practical implications of the new risk perspectives', Reliability Engineering and System Safety, Vol 115, pp 136-145, 2013.

19. T Aven and J-E Vinnem, Risk Management: With Applications from the Offshore Petroleum Industry, Springer, London, 2007.

20. Chrysler Corporation, Ford Motor Company, General Motors Corporation, 'Potential failure mode and effects analysis (FMEA) - reference manual', 1995.

21. R Jansen and R Karki, 'Sustainable energy optimisation in a smart microgrid', In: Sustainable Power Systems: Modelling, Simulation and Analysis, pp 111-132, Springer, Singapore, 2017.

22. R A González-Fernández and A M L da Silva, 'Reliability assessment of time-dependent systems via sequential crossentropy Monte Carlo simulation', IEEE Transactions on Power Systems, Vol 26, No 4, pp 2381-2389, 2011.

23. A Koltsidopoulos Papatzimos, T Dawood and P R Thies, 'An integrated data management approach for offshore wind turbine failure root cause analysis', Proceedings of the ASME 2017 36th International Conference on Ocean, Offshore and Arctic Engineering, Trondheim, Norway, 25-30 June 2017.

24. C C Ciang, J-R Lee and H-J Bang, 'Structural health monitoring for a wind turbine system: a review of damage detection methods', Measurement Science and Technology, Vol 19, No 12, pp 1-20, 2008.

25. A Niesłony, 'Determination of fragments of multiaxial service loading strongly influencing the fatigue of machine components', Mechanical Systems and Signal Processing, Vol 23, No 8, pp 2712-2721, 2009.

26. M A Miner, 'Cumulative damage in fatigue', Journal of Applied Mechanics, Vol 12, No 3, pp 159-164, 1945.

27. U R Bharadwaj, V V Silberschmidt and J B Wintle, 'A risk-based approach to asset integrity management', Journal of Quality in Maintenance Engineering, Vol 18, No 4, pp 417-431, 2012.

28. American Petroleum Institute, 'API 570 - piping inspection code: in-service inspection, rating, repair and alteration of piping systems', API Publishing Services, Washington, DC, 2016.

29. EDF Energy Renewables, 'Teesside offshore wind farm corrosion and cathodic protection, unpublished confidential document, 2012.

30. DNV, 'DNV-OS-J101 - Design of Offshore Wind Turbine Structures', 2007.

31. TWI Limited, 'Guidelines for use of statistics for analysis of 
sample inspection of corrosion', Crown, Norwich, 2002.

32. R Martin, I Lazakis, S Barbouchi and L Johanning, 'Sensitivity analysis of offshore wind farm operation and maintenance cost and availability', Renewable Energy, Vol 85, pp 1226-1236, 2016. 